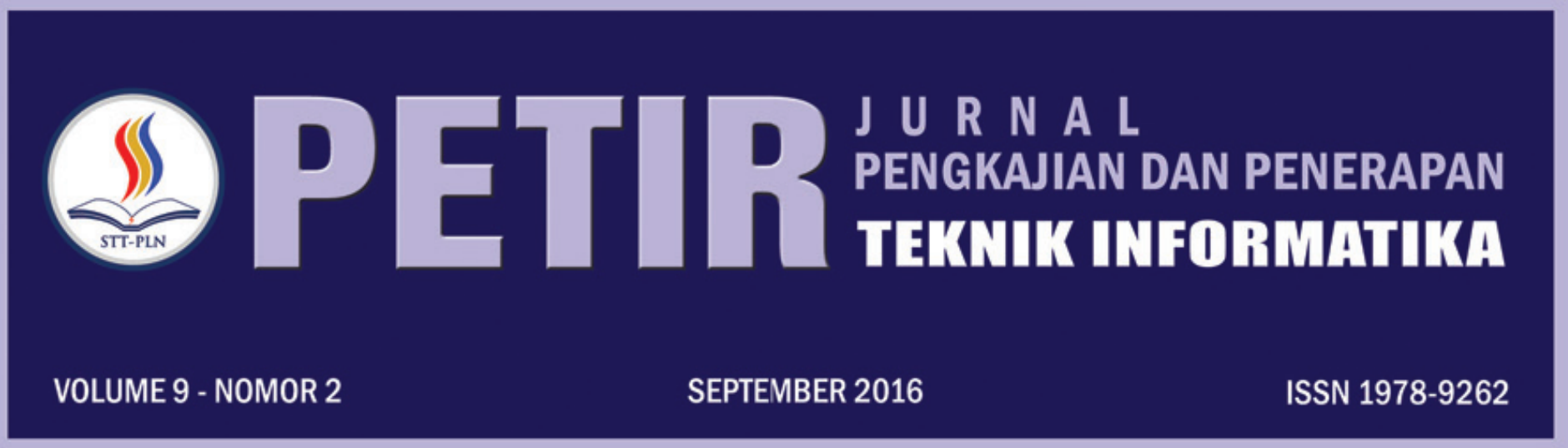

ANALISA SPASIAL UNTUK MELIHAT TINGKAT KESEJAHTERAAN MASYARAKAT DI PROVINSI BANTEN Muhamad Jafar Elly; Reza Pahlevi

PENENTUAN WILAYAH RAWAN PENYAKIT BERBASIS LINGKUNGAN DI JAKARTA TIMUR MENGGUNAKAN SISTEM INFORMASI GEOGRAFIS

Atiqah Meutia Hilda; Muhamad Jafar Elly; Windu Nugroho Cahyo Pamungkas

APLIKASI PENCARIAN USTADZ UNTUK WILAYAH DKI JAKARTA MENGGUNAKAN ALGORITMA HAVERSINE FORMULA BERBASIS ANDROID

Harni Kusniyati; Haries Fadhillah

PERENCANAAN ARSITEKTUR ENTERPRISE PERGURUAN TINGGI DENGAN PENDEKATAAN ENTERPRISE ARCHITECTURE PLANNING (EAP) (STUDI KASUS POLITEKNIK PIKSI GANESHA)

M. Farid Rifai

PERANCANGAN E-KATALOG PADA PERPUSTAKAAN DIGITAL STT-PLN BERBASIS WEB

Yessy Fitriani; Yasni Djamain; Risalatulina Dwi Kurniati

APLIKASI SISTEM GPS KEGIATAN OPERASIONAL PERSAMPAHAN DINAS PENGELOLAAN SAMPAH, PERTAMANAN DAN PEMAKAMAN (DP4) KOTA SUKABUMI

Yasmi Afrizal; Julian Chandra W
PERANCANGAN APLIKASI PENGOLAHAN DATA KAS BERBASIS ONLINE
(STUDI KASUS : KEMENTRIAN ' $X$ ')
Dian Hartanti; Lingga Desyanita

PERANCANGAN SISTEM INFORMASI PESERTA SERTIFIKASI

(Studi kasus LSP Piksi Ganesha)

Hendra Jatnika

RANCANG BANGUN APLIKASI SEC-WAY GUNA PENGINGAT BEPERGIAN DILENGKAPI INFO CUACA DAN CCTV JALAN RAYA LOKASI PILIHAN BERBASIS ANDROID STUDI KASUS DKI JAKARTA

Yasni Djamain; Intan Ratna Sari Yanti; Hari Wibowo

PREDIKSI PENERIMAAN SISWA BARU PADA MADRASAH ALIYAH AS-SAYAFI'IYAH 02 MENGGUNAKAN METODE TIME SERIES

Sarwo; Hermawan

PERANCANGAN SIMULASI MEDIA PEMBELAJARAN DENGAN METODE DIVISION REMAINDER UNTUK PENCARIAN ALAMAT RELATIF PADA PROSES PENEMPATAN DATA

Dewi Arianti Wulandari; Darma Rusjdi

ANALISIS SISTEM PENENTUAN LOKASI GANGGUAN JARINGAN DISTRIBUSI LISTRIK TERINTEGRASI GOOGLE MAP Abdul Haris; Herman Bedi Agtriadi

\begin{tabular}{|c|c|c|c|c|c|c|}
\hline \multirow{2}{*}{$\begin{array}{c}\text { ISSN } \\
|||||||||||||||||||||||||| \mid\end{array}$} & \multicolumn{6}{|c|}{ SEKOLAH TINGGI TEKNIK - PLN (STT-PLN) } \\
\hline & PETIR & VOL. 9 & NO. 2 & HAL. $89-166$ & JAKARTA, SEPTEMBER 2016 & ISSN 1978-9262 \\
\hline
\end{tabular}




\title{
RANCANG BANGUN APLIKASI SEC-WAY GUNA PENGINGAT BEPERGIAN DILENGKAPI INFO CUACA DAN CCTV JALAN RAYA LOKASI PILIHAN BERBASIS ANDROID STUDI KASUS DKI JAKARTA
}

\author{
Yasni Djamain, Intan Ratna Sari Yanti, Hari Wibowo \\ Teknik Informatika Sekolah Tinggi Teknik PLN \\ Email : yasnidj@yahoo.com , hari_wibowo15@yahoo.co.id
}

\begin{abstract}
Abstrak
Bepergian merupakan kebutuhan yang dilakukan oleh manusia sehari-hari. Banyaknya alat transportasi menyebabkan pilihan untuk bepergian menjadi lebih beragam. Akan tetapi, alat transportasi yang sering dipunyai oleh masyarakat perkotaan khususnya Kota Jakarta adalah kendaraan pribadi yaitu motor atau mobil. Banyaknya kendaraan pribadi menyebabkan pengendara harus merencanakan jadwal bepergian yang tepat sehingga perjalanan dapat lancar sesuai dengan rencana. Jadwal bepergian akan berfungsi jika penggunanya melaksanakan kegiatan dalam jadwal tersebut dan tidak jarang jadwal yang dibuat tidak terlaksana dengan baik, dimulai dari faktor pribadi, faktor lingkungan, sampai faktor kondisi di tempat tujuan. Penelitan dengan tahap mulai dari pengambilan data bepergian sangat dibutuhkan karena melihat di daerah ibukota yang kebanyakan memakai jalan raya untuk bepergian, sampai dari masalah tersebut di rancangnya aplikasi sec-way berbasis android diciptakan untuk membuat jadwal bepergian secara praktis dengan fitur pengingat dan informasi kondisi kota tujuan berupa suhu cuaca hari ini dan daftar CCTV kota tujuan. Secara garis besar aplikasi sec-way dalam penyediaan daftar kota tujuan tersebut mencari data alamat CCTV yang tersedia di masing-masing kota tujuan. Pembuatan aplikasi android dengan bahasa pemrograman java ini mengambil data dari penyedia CCTV dan cuaca yang valid dan dari kombinasi dari masukan kota awal ke kota tujuan diolah dengan metode sequential search untuk menampilkan daftar CCTV ke kota tujuan aplikasi sebagai informasi yang efektif dalam membuat terlaksananya jadwal bepergian.
\end{abstract}

Kata Kunci : Jadwal, Bepergian, CCTV, Pengingat, Smartphone, Android, Cuaca

\section{PENDAHULUAN}

\subsection{Latar Belakang}

Manusia pada umumnya adalah makhluk sosial dimana manusia membutuhkan aktivitas mulai dari bekerja sampai liburan. Aktivitas yang dilakukan untuk berpindah dari satu tempat ketempat lain merupakan keputusan yang harus diambil pada hari yang tepat agar terlaksana jadwal yang sudah dibuat, apalagi di daerah ibukota permasalahan untuk bepergian bukan hanya dari faktor dalam diri tetapi faktor dari lingkungan sekitar juga menyebabkan terlaksana atau tidak nya suatu jadwal bepergian yang telah dibuat jadwal bepergian kebanyakan bisa batal karena lupa, tidak sesuai jadwal, cuaca tidak mendukung, dan macet.

Dalam merencanakan suatu perjalanan bisa dapat terdapat kendala sulit di duga mulai dari faktor dalam diri dan faktor lingkungan, untuk itu dibutuhkan informasi lingkungan tempat tujuan sangat diperlukan. Informasi lingkungan lokasi tujuan sudah didapat maka akan memperjelas jadwal bepergian. Aplikasi yang diberi nama secway oleh penulis dengan fitur informasi cuaca dan lalu lintas setempat berbasis android studi kasus DKI Jakarta, dibuat untuk membantu pengguna menyesuaikan jadwalnya dengan lingkungan sekitar dan bisa dikatakan pula fungsinya seperti sekertaris pribadi untuk mengingatkan jadwal bepergian.

Aplikasi dengan nama sec-way (secretary on your way) sebagai aplikasi pengingat jadwal bepergian dengan keluaran mengetahui kondisi kota tujuan, pengguna akan menuliskan jadwal pada tanggal yang di sediakan lalu akan di sediakan pilihan wilayah kota pada DKI jakarta untuk bepergian dan ketika jadwal tersebut diingatkan kembali, muncul alarm maka aplikasi akan mencari data cuaca dan kumpulan CCTV lalu lintas dari kota pilihan pengguna yang letaknya di tentukan menggunakan oleh metode squential search untuk mendapatkan data CCTV yang sesuai karena pengecekan dilakukan satu persatu dari setiap elemen array dan menampilkannya sebagai informasi yang aktual.

Data di dapat dari server dan web yang menyediakan data atau konten CCTV jalan raya dan cuaca di masing-masing kota DKI Jakarta yang bisa di tampilkan bisa berupa peta CCTV jalan raya di DKI Jakarta dalam aplikasi pengingat ini, juga aplikasi ini di sertai notifikasi untuk bantuan pengingat si pengguna aplikasi yang suka bepergian antar kota di wilayah DKI Jakarta. Dengan aplikasi ini di harapkan tidak ada lagi kesulitanuntuk mengatur jadwal bepergian pada wilayah DKI Jakarta.

\subsection{Rumusan Masalah}

Berdasarkan dari uraian latar belakang di atas maka dapat dirumuskan suatu permasalahan, yaitu

Bagaimana membangun sistem aplikasi pengingat agenda bepergian berdasarkan lokasi kota pilihan berbasis android studi kasus DKI Jakarta, ketika menampilkan detail jadwal perjalanan dapat menampilkan informasi cuaca dan tampilan CCTV jalan raya sesuai kota pilihannya? 


\subsection{Tujuan penelitian}

Penulisan ini bertujuan untuk :

1) Membuat aplikasi pengingat jadwal bepergian di wilayah DKI Jakarta

2) Menyediakan informasi cuaca dan tampilan CCTV jalan raya kelokasi pilihan di wilayah DKI Jakarta.

3) Aplikasi yang unggul dalam mencatat jadwal bepergian dan menampilkan informasi daerah tujuan diharapkan menjadi aplikasi yang selalu dibutuhkan seperti sekertaris pribadi.

\section{LANDASAN TEORI}

\subsection{Manajemen Waktu}

Manajemen Waktu didefinisikan sebagai kemampuan untuk memprioritaskan, menjadwalkan, melaksanakan, dan melaksanakan tanggung jawab individu demi kepuasan individu tersebut. Waktu sebagai kuantitas yang dapat diukur adalah konsep buatan. Detik, jam, hari, bulan, dan tahun merupakan kreasi pikiran manusia. Hitungan waktu adalah bentuk upaya untuk meneraturkan kekacauan (Widyastuti, 2004).

\subsection{Prakiraan Cuaca}

Prakiraan cuaca merupakan ilmu peramalan cuaca yang bercabang dari meteorologi, yaitu ilmu yang mempelajari atmosfer dan proses yang terjadi di dalamnya. Peramalan cuaca juga didukung oleh ilmu lain, yaitu klimatologi atau ilmu yang mempelajari keadaan rata rata dan ekstrim, frekuensi, serta persebaran berbagai unsur cuaca(Pujiastuti, 2007).

\subsection{Lalu Lintas}

Informasi yang di tampilkan dalam aplikasi Sec-way nantinya diharapkan memberikan info CCTV jalan raya kepada pengguna yang menentukan jadwal bepergian di hari itu, tentang suasana lalu lintas pada daerah tujuan yang sudah diinputkan pada menu pilihan wilayah berdasarkan Provinsi DKI Jakarta. Suasana yang terjadi contohnya berupa konten informasi lalu lintas yang terkait pada jalanan DKI Jakarta apakah macet, lancar, atau terjadi masalah karena faktor cuaca. Tentunya pengguna aplikasi akan lebih terbantu dalam melaksanakan jadwal yang ada di aplikasi Sec-way dengan informasi lalu lintas tersebut.

\subsection{Bepergian}

Definisi bepergian adalah berpindah dari satu tempat ke tempat lainnya untuk mencapai suatu tujuan materi atau immateri (Ash-sha'idi, 1998).

\subsection{CCTV (Closed Circuit Television)}

Merupakan seperangkat penangkap objek yang terdiri atas kamera dan display(dapat berupa monitor atau televisi). Umumnya perangkat ini di aplikasikan pada jaringan privat dan tertutup untuk publik sehingga tidak dapat di akses secara bebas kecuali oleh pihak pihak yang memiliki otoritas.

Perangkat ini biasa di aplikasikan sebagai perlengkapan monitoring dan keamanan. Hingga saat ini pun tetap dipergunakan dengan penambahan beberapa kemampuan seperti teknik wireless yang memanfaatkan udara sebagai media transisi (Amir, 2010).

\subsection{Tugas Sekertaris}

Pimpinan sehebat apapun, dia tetap membutuhkan seseorang untuk membantu kegiatan yang harus dilakukan dan menyusunnya dalam sebuah jadwal kegiatan. Dengan demikian, pimpinan dapat berkonsentrasi dengan pekerjaannya tanpa harus mengingat apa saja kegiatan yang harus diselesaikan dalam satu hari atau satu minggu. Untuk itu peran seorang sekertaris dibutuhkan untuk selalu membantu pimpinan dalam menyusun jadwal kegiatan pimpinan (Sumarto, 2005).

\subsection{Android}

Android adalah sebuah sistem operasi untuk perangkat mobile berbasis linux yang mencakup sistem operasi, middleware dan aplikasi. Android menyediakan platform terbuka bagi para pengembang untuk menciptakan aplikasi pengguna sendiri (Suratmo, 2012).

\subsection{Pencarian Berurutan (Sequential Searching)}

Pencarian Berurutan (Sequential Searching) Pencarian berurutan sering disebut pencarian linear merupakan metode pencarian yang paling sederhana. Pencarian berurutan menggunakan prinsip sebagai berikut : data yang ada dibandingkan satu per satu secara berurutan dengan yang dicari sampai data tersebut ditemukan atau tidak ditemukan. Pada dasarnya, pencarian ini hanya melakukan pengulangan dari 1 sampai dengan jumlah data. Pada setiap pengulangan, dibandingkan data ke-i dengan yang dicari. Apabila sama, berarti data telah ditemukan. Sebaliknya apabila sampai akhir pengulangan tidak ada data yang sama, berarti data tidak ada. Pada kasus yang paling buruk, untuk $\mathrm{N}$ elemen data harus dilakukan pencarian sebanyak $\mathrm{N}$ kali pula (Sitorus, 2015).

\subsection{Quota Sampling}

Quota sampling adalah teknik untuk menentukan sampel dari populasi yang mempunyai ciri-ciri tertentu sampai jumlah (kuota) yang diinginkan dan temasuk dalam nonprobabilitas sampling.Dalam teknik ini jumlah populasi tidak diperhitungkan akan tetapi diklasifikasikan dalam beberapa kelompok. Sampel diambil dengan memberikan jatah atau quorum tertentu terhadap kelompok. Pengumpulan data dilakukan langsung pada unit sampling.Setelah kuota terpenuhi pegambilan sampel dapat dihentikan (Sugiyono, 2008).

\subsection{Personal Extreme Programming (PXP)}

Extreme Programming $(X P)$ adalah sebuah model pengembangan perangkat lunak yang menyederhanakan berbagai tahapan dalam proses pengembangan sehingga menjadi lebih adaptif dan fleksibel. Di dalam perkembangannya, $X P$ bisa dikembangkan ke dalam beberapa metode, antara lain Practices $X P$. Practices $X P$ dapat diterapkan 
untuk menangani situasi proses pengembangan perangkat lunak dengan pemrogram tunggal, yang kemudian dinamakan dengan metodologi Personal Extreme Programming (PXP) (Sandika \& Kurniawan, 2014 ).

Personal Extreme Programming Practices XP dapat diterapkan untuk menangani situasi proses pengembangan perangkat lunak dengan pemrogram tunggal, yang kemudian dinamakan dengan metodologi Personal Extreme Programming (Rizal, Adhy, \& Wirawan, 2015).

Metode Personal Extreme Programming $(P X P)$ merupakan metode hasil pengembangan dari metode Extreme Programming $(X P)$. Metode $P X P$ mempunyai keunggulan dari sisi kecepatan, dengan menggunakan $P X P$ maka siklus hidup perangkat lunak menjadi lebih cepat, dikarenakan penyederhanaan dari metode $X P$. Metode $P X P$ memudahkan software developer dalam melakukan pengembangan perangkat lunak, karena waktu siklus hidup yang cepat serta fase-fase yang tidak terlalu banyak (Sandika \& Kurniawan, 2014 ).

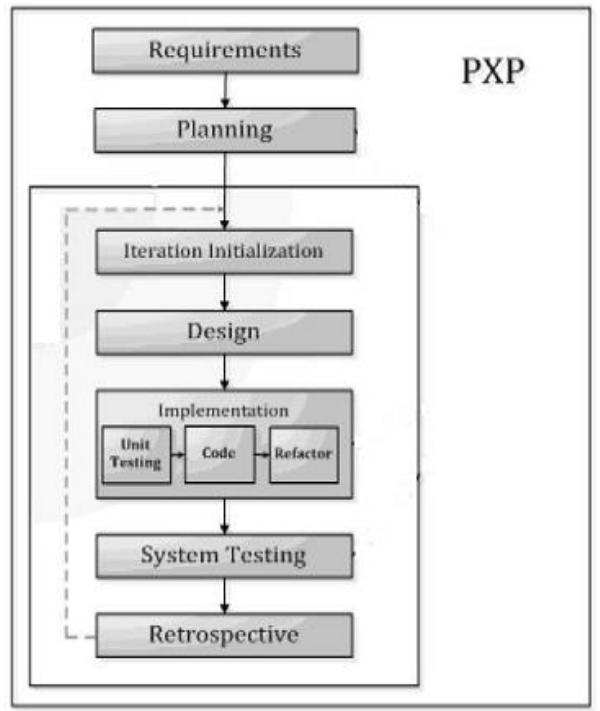

Gambar 1. Fase Proses Pxp

\section{METODE PENELITIAN}

Tahapan penelitan untuk perancangan aplikasi ini akan menggunakan metode personal extreme programming. Metode personal extreme programming $(P X P)$ adalah sebuah pendekatan pengembangan perangkat lunak yang mencoba meningkatkan efisiensi dan fleksibilitas dari sebuah proyek pengembangan perangkat lunak dengan mengkombinasikan berbagai ide sederhana yang ada didalamnya sehingga menjadi lebih adaptif. Berikut penyesuaian dari metode personal extreme programming ke dalam penulisan penelitian ini :

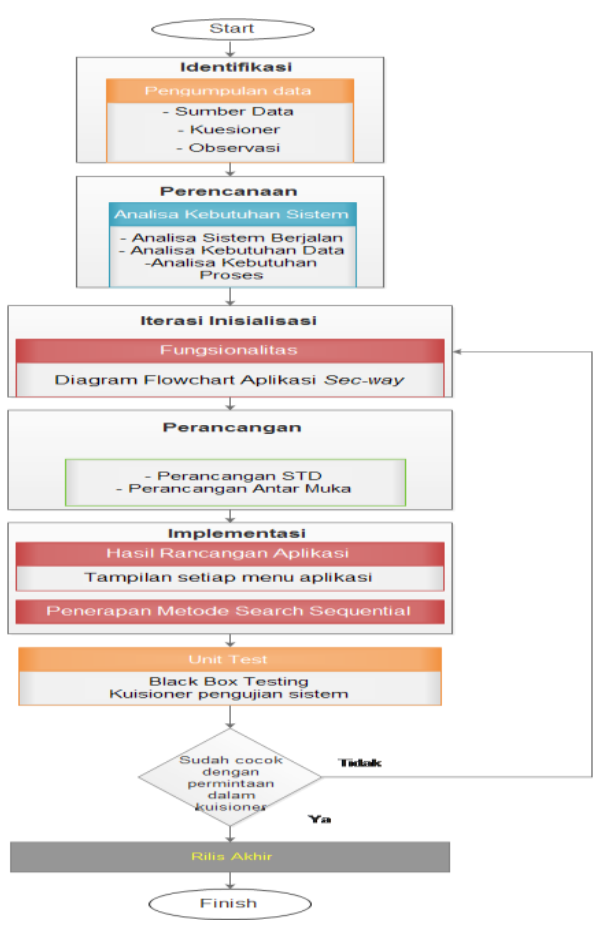

Gambar 2. Alur Penerapan Metode PXP

1) Identifikasi. Bagian tahapan requirements dari PXP, dilakukan pembentukan arsitektur program berdasarkan data observasi untuk identifikasi kebutuhan data di aplikasi juga identifikasi pengguna sistem dengan menerapkan kuesioner terhadap calon pengguna aplikasi.

2) Perencanaan. Bagian tahapan planning dari $P X P$, penentuan fungsionalitas keseluruhan dari jadwal bepergian yang akan dikembangkan dalam sistem diterapkan pada analisa sistem usulan.

3) Inisalisasi iterasi. Fungsionalitas yang sudah dibentuk dari analisa kebutuhan dijabarkan menjadi terperinci, dibuat dalam bentuk flowchart aplikasi sec-way.

4) Perancangan penelitian. Bagian tahapan design dari $P X P$, Solusi rancangan diterapkan tidak keluar dari dengan ruang lingkup penelitian Merancang menggunakan STD dan perancangan antar muka aplikasi

5) Implementasi. Dari perancangan aplikasi lalu dibuat dengan pengkodean menggunakan bahasa java yang menghasilkan tampilan menu aplikasi berbasis android.

6) Unit tes. Bagian tahapan system testing dari $P X P$, untuk pengecekan fungsionalitas yang diterapkan kedalam aplikasi sec-way sudah berjalan baik atau belum, dan sesuai dengan penjabaran flowchart terhadap fungsi yang dibutuhkan dalam sistem usulan. Jika tahapan belum sesuai maka kembali lagi ke inisialisasi iterasi untuk membuat fungsi berjalan sesuai hasil penentuan fungsionalitas.

7) Rilis akhir. Setelah tahapan unit tes berjalan sesuai yang diinginkan maka aplikasi sec-way siap digunakan atau dilakukan pada tahap pemeliharaan selanjutnya. 


\section{HASIL DAN PEMBAHASAN}

\subsection{Identifikasi}

\subsubsection{Kuesioner}

Metode kuesioner ini merupakan pegumpulan data berupa responden dari pertanyaan tentang kebutuhan akan aplikasi sec-way. Tehnik ini merupakan pendapat calon pengguna aplikasi yang data pendapatnya akan dibuat pendukung untuk terciptanya setiap fitur aplikasi sec-way. Data kuisioner yang di dapat dari pengguna jalan raya di provinsi DKI Jakarta, sampel yang ditentukan berdasarkan metode Quota sampling, dari populasi pengguna jalan raya di wilayah DKI Jakarta penulis memilih 50 orang sebagai responden di kuesioner ini.

\subsubsection{Data Primer}

Adalah data yang diperoleh secara langsung dari sumber, misalnya data data hasil diskusi langsung dengan user pengguna aplikasi referensi dan membaca konten setiap data yang di perlukan dari open data weather dan CCTV ip streaming DKI Jakarta.

Tabel 1. Kebutuhan Data Primer

\begin{tabular}{|c|c|c|c|}
\hline No. & Nama Data & Atribut & Deskripsi \\
\hline 1. & $\begin{array}{l}\text { Tampilan } \\
\text { CCTV } \\
\text { Jalan Raya } \\
\text { DKI } \\
\text { Jakarta }\end{array}$ & $\begin{array}{l}\text { a. IP address } \\
\text { CCTV } \\
\text { b. CCTV } \\
\text { format.PNG file } \\
\text { c. CCTV } \\
\text { format.MJPEG } \\
\text { file } \\
\text { d. Alamat } \\
\text { Lokasi CCTV } \\
\text { jalan raya DKI } \\
\text { Jakarta }\end{array}$ & $\begin{array}{l}\text { Tampilan } \\
\text { dibutuhkan } \\
\text { untuk informasi } \\
\text { kondisi jalan } \\
\text { raya di fitur } \\
\text { CCTV jalan } \\
\text { raya. } \\
\text { Sebagai } \\
\text { informasi } \\
\text { pendukung } \\
\text { jadwal } \\
\text { bepergian }\end{array}$ \\
\hline 2. & $\begin{array}{l}\text { Data } \\
\text { Cuaca } \\
\text { Terkini di } \\
\text { DKI } \\
\text { Jakarta }\end{array}$ & $\begin{array}{l}\text { a. Weather API } \\
\text { key } \\
\text { b. Suhu cuaca } \\
\text { dalam celcius } \\
\text { c. Icon Status } \\
\text { Cuaca }\end{array}$ & $\begin{array}{l}\text { API Key di } \\
\text { butuhkan } \\
\text { untuk } \\
\text { mengakses } \\
\text { data yang } \\
\text { diberikan } \\
\text { penyedia info } \\
\text { prakiraan } \\
\text { cuaca berbasis } \\
\text { android. }\end{array}$ \\
\hline
\end{tabular}

\subsection{Perencanaan}

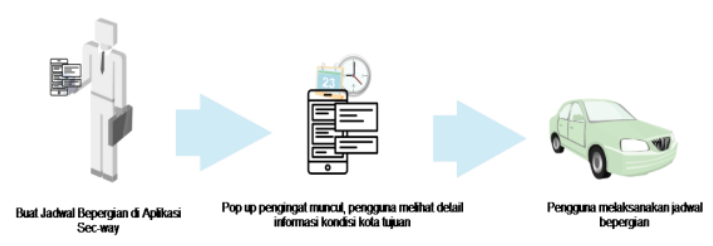

Gambar 3 Alur Sistem Usulan Sec-Way

Dari analisis tersebut dan hasil kuesioner yang didapat, solusi dari penulis untuk membuat fitur di aplikasi pengingat bepergian :

1) Membuat daftar jadwal di aplikasi sec-way berbasis android.
2) Fitur notifikasi untuk pengingat sesuai inputan waktu dari pengguna.

3) Menampilkan informasi cuaca di wilayah dki jakarta sesuai dengan hari dimana detail jadwal dilihat.

4) Menampilkan informasi kondisi jalan raya dengan penyajian daftar CCTV ke kota tujuan.

\subsection{Inisalisasi iterasi}

Pada tahap ini Fungsionalitas yang sudah dibentuk dari analisa kebutuhan dijabarkan menjadi terperinci, dibuat dalam bentuk flowchart aplikasi sec-way:

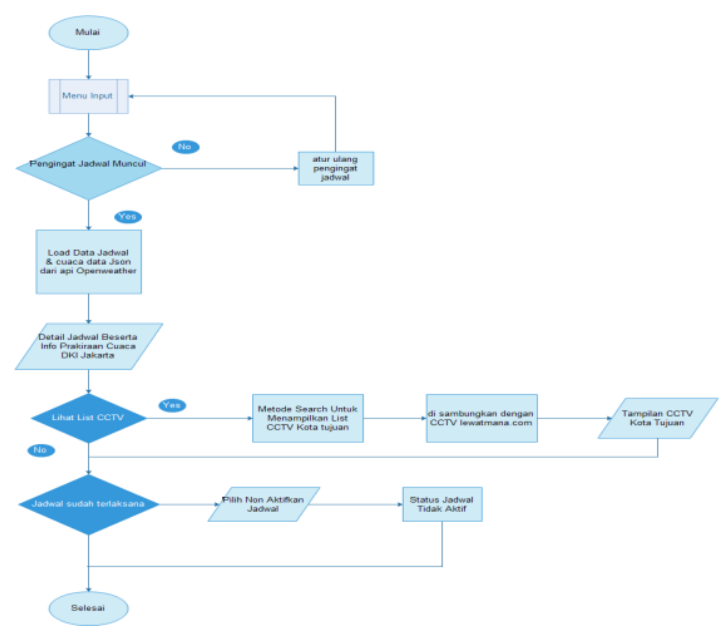

Gambar 4. Perancangan Flowchart

\subsection{Perancangan penelitian}

Tahap ini terdapat Solusi rancangan diterapkan tidak keluar dari dengan ruang lingkup penelitian, merancang menggunakan STD dan perancangan antar muka aplikasi. Rancangan STD dapat kita lihat di gambar berikut:

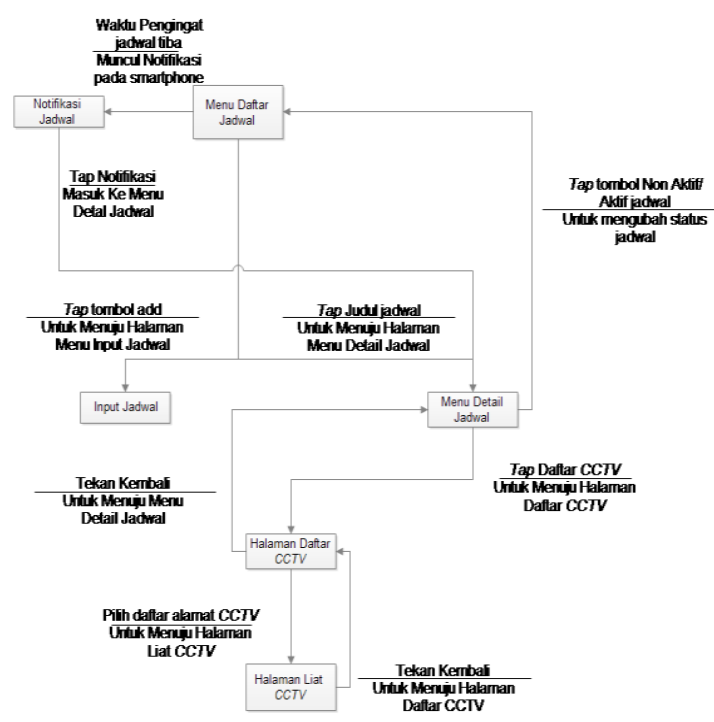

Gambar 5. Perancangan State Transition Diagram

Rancangan antar muka aplikasi di bagian menu daftar jadwal dan menu detail jadwal di gambarkan sebagai berikut: 


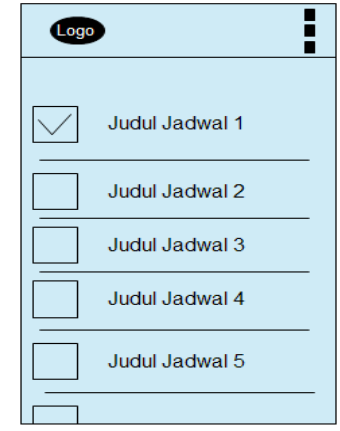

Gambar 6. Perancangan State Transition Diagram

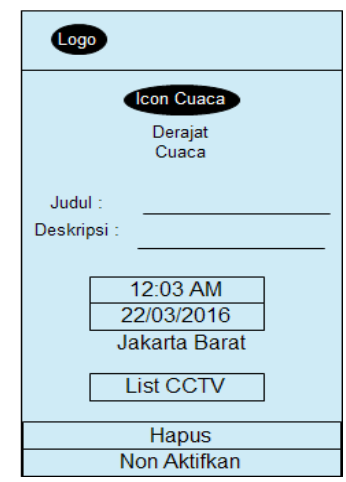

Gambar 7. Perancangan State Transition Diagram

\subsection{Implementasi}

Pada tahap ini, mulai dilakukan pengodean sistem. Hasil implementasi dapat dilihat pada gambar berikut :

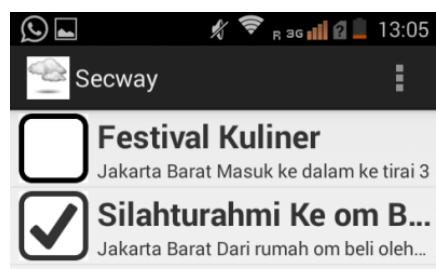

Gambar 8. Tampilan Menu Daftar Jadwal Terisi

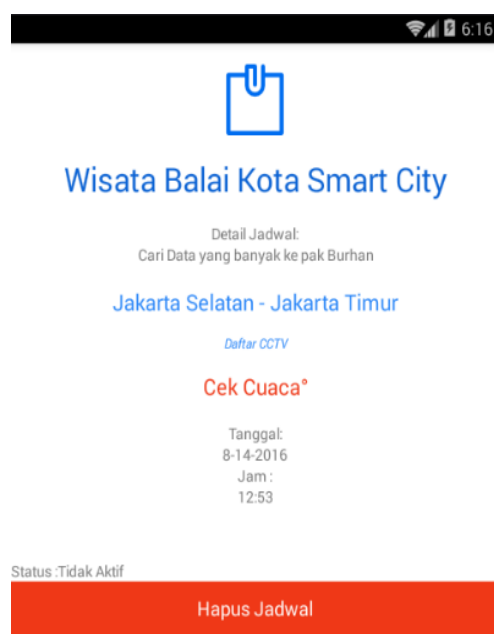

Gambar 9. Tampilan Menu Detail Jadwal

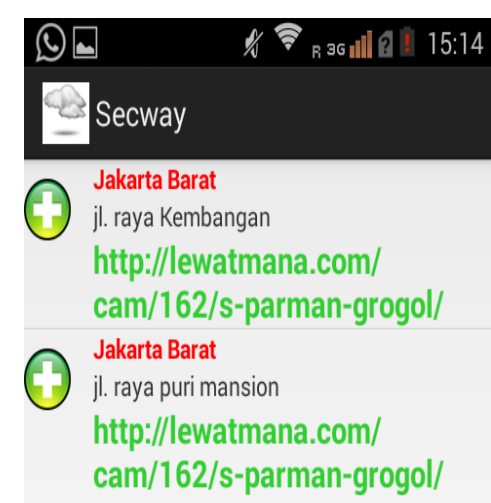

Gambar 10. Tampilan Menu Daftar CCTV Ke Kota Tujuan

Metode yang di terapkan pada pengkodingan aplikasi untuk mencari apakah kombinasi dari kota sekarang dan kota tujuan ada dalam data daftar CCTV yang dibuat penulis atau tidak, dengan menggunakan metode sequential search pada semua elemen array yang dimulai dari index 0 sampai index 24 yang berisikan kode kombinasi kota sekarang dan kota tujuan yang sudah ada dalam data aplikasi, kemudian mecocokan dari input pembuatan jadwal dalam penentuan kota sekarang dan kota tujuan barulah dimunculkan daftar CCTV dari kota sekarang ke kota tujuan dengan berdasarkan letak jalan protokol yang mengarah ke kota tersebut. Data observasi yang penulis lakukan pada penyedia data CCTV lewatmana.com menjadi acuan dari letak CCTV yang dimunculkan.

Tabel 2. Kombinasi Inputan Kota Di Dki Jakarta

\begin{tabular}{|l|c|c|c|c|c|}
\hline \multicolumn{1}{|c|}{ Jakarta } & $\begin{array}{c}\text { Timur } \\
(1)\end{array}$ & $\begin{array}{c}\text { Selatan } \\
(2)\end{array}$ & $\begin{array}{c}\text { Barat } \\
(3)\end{array}$ & $\begin{array}{c}\text { Utara } \\
(4)\end{array}$ & $\begin{array}{c}\text { Pusat } \\
(5)\end{array}$ \\
\hline Timur (1) & 11 & 12 & 13 & 14 & 15 \\
\hline Selatan (2) & 21 & 22 & 23 & 24 & 25 \\
\hline Barat (3) & 31 & 32 & 33 & 34 & 35 \\
\hline Utara (4) & 41 & 42 & 43 & 44 & 45 \\
\hline Pusat (5) & 51 & 52 & 53 & 54 & 55 \\
\hline
\end{tabular}

\subsection{Unit Test}

Menguji sistem digunakan BlackBox testing. Kriteria yang diuji ada 4 kriteria yaitu fungsi yang tidak benar atau hilang, kesalahan antarmuka, kesalahan struktur data atau akses database eksternal, dan kesalahan kinerja.

\subsection{Rilis Akhir}

Hasil Pengujian menunjukkan bahwa sistem yang dibangun berfungsi dengan baik. Aplikasi android sec-way siap rilis.

\section{KESIMPULAN}

Dari hasil penelitian yang dilakukan dari tahap awal hingga proses pengujian, dengan adanya aplikasi ini dapat disimpulkan bahwa : 
1) Menampilkan kondisi ke kota tujuan dengan daftar CCTV didapat dari penyedia layanan CCTV lewatmana.com berdasarkan jalan raya yang menghubungkan dari kota awal ke kota tujuan.

2) Fitur informasi suhu cuaca di DKI Jakartasaling mendukung dengan informasi tampilan CCTV kota tujuan di DKI Jakarta. Pengguna bisa mempersiapkan jadwal bepergiannnya lebih matang setelah menggunakan aplikasi sec-way.

3) Perancangan aplikasi ini dibuat berbasiskan android dengan kemudahan penggunaanyamembawa smartphone sebagai pengingat jadwal bepergian untuk aplikasi yang bisa digunakan setiap hari, diibaratkan sebagai sekertaris bepergian si pengguna.

\section{DAFTAR PUSTAKA}

Abidin, H. (2007). Penentuan Posisi Dengan Menggunakan GPS dan Aplikasinya. Bandung: PT Pradyan Paramita.

Amir, M. A. (2010). IP Camera dan Aplikasinya. Jakarta: Elex Media Komputindo.

Android Studio. (2016, June 20). Index of Developer Android Website. Retrieved from Developer Android Website: https://developer.android.com/studio/intro/inde x.html

EdrawSoft. (2004, 01 27). About Us: Edraw Max. Retrieved from Edraw Max: https://www.edrawsoft.com/EDrawMax.php

Fowler, M. (2005). UML Distilled 3th Ed. , Panduan Singkat Bahasa Pemodelan Objek Standar. Yogyakarta: ANDI.

Gumelar, C. (2012). Sistem Informasi Transportasi di Palembang Berbasis Android pada PT. Sarana Pembangunan Palembang Jaya. Palembang: STMIK GI MDP.

Hartono, J. (1999). Pengenalan Komputer. Yogyakarta: Andi offset.

Herlambang, S., \& Tanuwijaya, H. (2005). Sistem Informasi : Konsep, Teknologi dan Manajemen. Yogyakarta: Graha IImu.

Kadir, A. (2003). Pengenalan Sistem Informasi. Yogyakarta: Andi offset.

Kumura, K. W. (2011). SISTEM PELACAKAN POSISI BUS TRANS JOGJA BEBRBASIS MOBILE DAN WEB SERVER.

LAB-RPL. (2013, September 14). Extreme Programming / Laboraturium Rekayasa Perangkat Lunak. Retrieved December 10, 2015, from Laboraturium Rekayasa Perangkat Lunak: http://rpl.if.its.ac.id/extremeprogramming/

Lewatmana.com. (2008). Retrieved 32 , 2016, from Lewatmana.com: http://lewatmana.com/download/
National Safety Council. (2004). Management Stress. Jakarta: EGC.

Nistanto, R. K. (2013). Cal. Retrieved november 12 , 2015, from

http://tekno.kompas.com/read/2013/12/07/091 4445/ini.dia.aplikasi.pintar.pencatat.jadwal.di.a ndroid

Permadi, D. Y. (2011). Monitoring Kamera Pengawas Menggunakan Perangkat Dengan Sistem Operasi Android. Jakarta.

Prakoso, T. (2014). Google Keep Update, http://www.aplikanologi.com/produktivitas/goo gle-keep-update-dengan-tambahan-3-fiturbaru/.

Prastowo, B. N. (2016, 1 27). staff ugm. Retrieved from staff ugm website: http://prastowo.staff.ugm.ac.id/?modul=baca\& dir=artikel\&artikel=Dasar-Dasar-SistemInformasi

Pujiastuti, Y. S. (2007). IPS Terpadu 1B. Jakarta: Erlangga.

Ridwantrisna. (2013, 12 1). blog amikom. Retrieved from blog amikom website: http://phonegap.blog.amikom.ac.id/2013/12/01 /phonegap-pwl/

Rubin, A. (2007, 11 5). Retrieved from Official Google Blog: https://googleblog.blogspot.co.id/2007/11/whe res-my-gphone.html

Safaat, N. (2013). Android - Pemrograman Alikasi Mobile Smartphone dan Tablet PC Berbasis Android. . Bandung: Informatika.

SIGI, A. L. (2015). PERANCANGAN APLIKASI SARANA DAN RUMAH TANGGA (Studi Kasus : Laboratorium Komputer Lanjut). Jakarta: Tenik Informatka STTPLN.

Sigi, A. L. (2015). Perancangan Aplikasi Sarana Dan Rumah Tangga Laboratorium Komputer Teknik Informatika STT-PLN. Teknik Informatika STT-PLN .

Sitorus, L. (2015). Algoritma dan Pemrograman. Yogyakarta: Andi.

Sugiyono. (2008). Metode Penelitian Kuantitatif, Kualitatif dan R\&D. Bandung: Alfabeta.

Suprapta, E. C. (2012). Mahasiswa Politeknik Elektronika Negeri Surabaya. Surabaya: PENS-ITS Surabaya.

Suratmo, D. (2012). Proposal Skripsi Pembuatan Aplikasi Informasi Lokasi Perguruan Tinggi DI Yogyakarta Berbasis Web GIS. Yogyakarta.

Triyanto, T. (2014). E-Budgeting Dengan Menggunakan Metode Extreme Programming. Jakarta: Program Pascasarjana Magister IImu Komputer Nusa Mandiri.

WebHozz. (2016). Android Development PART 2. Jakarta: WebHozz.

Wells, D. (1999). Retrieved from http://www.extremeprogramming.org/rules.htm I

Widyastuti, P. (2004). Management Stress. Jakarta: EGC. 